And he is as good as his word! As a lawyer as well as a doctor - he is Deputy Chairman, Department of Legal Medicine, Armed Forces Institute of Pathology, and Professional Lecturer at the George Washington University National Law Center - he is conscious of the problem of teaching law to doctors (try putting it the other way round) or whether indeed such a feat would be necessary even if it were possible. But he does see that in the face of increasing pressure from patients on their doctors through the courts, a recognisable standard of professional behaviour is needed. Such a standard must come less from a sense of what the doctor believes his duty to be than from what the law prescribes as reasonable conduct under the circumstances of each particular case.

This book is not therefore a legal textbook in the strict sense of the word, but a collection of nearly 300 illustrations taken from cases in medical negligence decided in the American courts, most of them in the last ten years; a series of cautionary tales, if you will, against which readers may measure their own standards and maybe pick up a good deal of information on matters which up to the time of reading they had never thought could lay themselves open to criticism.

Most of the cases selected are for private reading and the rest are for group discussion, but the presentation is uniform; the facts are followed by the decision and the reason for the decision. The cases are not quoted verbatim, neither in whole nor in part, but are described in Dr Fiscina's own words. He eschews legal terminology, and makes no formal attempt to include matters of a procedural nature, such as the quantum of damages. But since he provides an index of the cases with references to the law reports, they may be followed up by anyone with the mind to do it, and with access to the American sources.
The selection covers a wide variety of medical circumstances, demonstrating an equally wide spectrum of conduct, from the outrageous to the highly commendable. They centre mainly on matters arising out of an individual doctor's behaviour, but they also relate, for example, to interlocking responsibilities in hospitals. They are arranged under specific headings covering all aspects of the doctor-patient relationship.

The lawyer wishing to dip his toe into the turbid waters of medical negligence may find this book useful as an introduction to the nature and scope of the matters in contention, which in America would seem to have reached a degree of sophistication not yet manifested here. He will also be interested to note how legal concepts in contract and tort revive with a transfusion of medical ethics.

SHELAGH GASKILL Faculty of Law The University of Leeds

\section{Philosophy in Medicine: Conceptual and Ethical Issues in Medicine and Psychiatry}

Charles M Culver and Bernard Gert New York, Oxford University Press, 1982

$£ 15.50$

Doctors are more cautious than they were in the nineteen-sixties, in the hubristic era, but the humility that has developed, although welcome, is for most a scientific humility, an increase in respect for the complexity of the human body and mind and the difficulties in trying to improve its function. Scientific humility, and the resultant caution, though welcome, are however, not sufficient. Doctors also need a much broader perspective than the scientific perspective. A higher proportion of doctors are now aware of the social and political implications of medicine but only a few are particularly well educated in more abstract issues.

The growth of interest in medical ethics has been welcome but ethics is only one aspect of philosophy and this book attempts to cover certain other aspects, although it is not a comprehensive text on philosophy in medicine. Four principal subjects are discussed. The first is the definition of rationality and the consequent implications for the assessment of competence. Related to this subject is a consideration of paternalistic behaviour and involuntary hospitalisation.

The third is a discussion of the nature and classification of 'maladies', focusing in particular on 'mental maladies' and 'volitional disabilities'. The fourth subject is 'the definition and criterion of death'.

The authors both work in Darmouth College and Medical School, one as a professor of psychiatry, the other as a professor of philosophy, and the text is based on the teaching they have done. It is clearly written and makes good use of case studies but its applicability to problems in other countries is limited. Philosophical principles, of course, should transcend all cultural barriers but many of the issues they discuss are in the context of the American legal system or the classification of diagnoses published by the American Psychiatric Association and thus relate to the way in which philosophical problems manifest themselves in American society.

Nevertheless, any British reader interested in any of the four subjects discussed in the book would find it worth consulting.

DR MUIR GRAY Community Health Offices The Radcliffe Infirmary Oxford 